\title{
EL CUERPO Y EL DEPORTE EN LA SOCIEDAD MODERNA
}

\author{
José M. Cagigal \\ (Instituto Nacional de Educación Física)
}

\section{EL HOMBRE ANTE SU CUERPO}

En medio de una cultura occidental casi radicalmente intelectualizada, el gran movimiento social del deporte en los dos últimos siglos ha venido a significar, al menos en los círculos intelectualizantes, la cultura o subcultu; ra del cuerpo; o, quizás, un movimiento actiltural potenciado por inter reses ecoriómicos y políticos, cuya presencia se agiganta con el correr del siglo $\mathrm{Xx}$.

Cultura, en la larga tradición maniqueo-cartesiana, ha sido -y así se ha mamado desde la primera escuela- intelectualización, abstracción, desartollo exclusivo de la mente, memorización, nocionalización, posesión de saberes. La revolución científica desde el xvi introdujo la objetivación, la prueba y el dato. Sirvió egregiamente para interpretar con más realismo el cosmos, pero no el hombre; a lo sumo, se han multiplicado los datos sobre el hom. bre, pero no se ha avanzado mucho en comprender al hombre; éste sigue siendo casi tanto misterio hoy como en Platón. Porque la ciencia moderna, en cuanto ha enfocado al hombre, ha continuado maniquea. Las ciencias de la conducta, por ejemplo, se han hipotecado viviendo del préstamo de las ciencias de la naturaleza. Están aún por nacer las metodologías verdadetamente originales de la ciencia del hombre. La línea de la llamada psicología cognitiva marca quizás un intento de originalidad científica en esta com. prensión. Pero es posible que tal originalidad no se logre hasta que se 
acepte un replanteamiento cultural del hombre.' Uno de los pasos que podrían ayudar a esta visión cultural neohumanista acaso fuese la aceptación del cuerpo como plena realidad humana. No quiere esto necesariamente decir como única, absoluta o exclusiva tealidad humana.

El cuerpo como soporte del espiritu, como condicionamiento, como sustrato, base, introito, trampolín (no digamos como rapto, cautividad, destietro, cárcel) no sólo ha estado presente en formulaciones filosóficas y ascéticas, sino que continúa viviendo, actuando, en el lenguaje, en concreciones institucionales, en sistemas educativos. $Y$ es precisamente en algunas corrientes pedagógicas actuales donde se pueden rastrear indicios radicales de una nueva manera de entender al hombte precisamente a partir de una nueva aceptación del cuerpo. Una vez más los pensadores irían detrás de los grandes intuitivos de la educación. En realidad los grandes intuitivo-prácticos no son sino grandes sensibilidades, grandes inteligencias sintéticas estimuladas por el reto de la acción educativa, aunque ellos no sean luego capaces de sistematizar mentalmente sus hallazgos y lo hayan de hacer otros. Rousseau sería una excepción.

Las actuales escuelas psicomotricistas, preñadas de ingenuidades, sim. plificaciones, oportunismos, tópicos y hasta de mesianismos, aportan un algo original cargado de valor antropológico y filosófico: la acción corporal es también inteligencia. No es que el mejoramiento del cuerpo mejore un trascendental soporte de las cualidades superiores, y, consecuentemente, éstas salgan favorecidas. No hay un tratamiento del cuerpo independiente del tratamiento de la persona. Todo tratamiento corporal es personal; incide directamente en las capacidades generales de la persona, en el desarrollo total.

Sigue siendo el lenguaje la muestra suprema de la corticalización; pero hoy se medita en el dato de que los responsables encefálicos de la acción manual también tienen enorme extensión cortical. La sensoperceptividad y la motricidad ocupan extensas zonas de privilegio neocortical en la gran escena intracraneal. Habían sido pedagogos prácticos los que ya habían experimentado la estrecha relación entre acción corporal (siempre hablamos de la bumana, que no es simplemente la animal que sirve a funciones supe-

1. Por no decir «filosófico», puesto que no se trataría de regresar a antiguos presupuestos filosóficos, sino al hallazgo del hombre ya desde los datos actuales de las ciencias. Un descubrimiento «cultural» del hombre, qque podría coincidir con soluciones heraclitianas, parmenidianas, aristotélicas, pero que nunca serían ya neoheraclitismos o neoplatonismos, sino una comprensión más rica del hombre a partir de nuevos presupuestos científicos y culturales, de la cual no hay que presuponer a priori que haya de disentir radicalmente de lo que entendieron hombres eminentes que pensaban acerca del hombre. 
riores de la mente, sino que es ya, desde las más groseras acciones motrices, plenamente humana, humanizada) y progreso mental; incluso se habian ob. servado las incidencias en el área afectiva. Pero han sido las observaciones metódicas de los estudiosos de la psicología del desarrollo los que han venido a respaldar aquellos hallazgos. $\mathrm{La}$ importancia radical que Piaget atribuye a la acción mottiz en las primetas épocas del desatrollo mental, y la influencia notable que sigue ejerciendo durante un largo período evolutivo, ha supuesto un decisivo espaldarazo a tan notables intuiciones. Consecuencias análogas se derivan de las investigaciones de neuropsicólogos como Luria. Pedagogos, puericultores, psicólogos, psicoterapeutas, pediatras, educadores físicos, vienen ahora a coincidir en la búsqueda y experimentación de esta fecunda veta psicomotricista, que algunos elevan a talismán.

Desde otros campos de la investigación y práctica pedagógica se com* prueban análogos hallazgos; así en los numetosos estudios que en las escuelas americanas de aprendizaje motor se vienen haciendo en las túltimas décadas. Cortelaciones positivas entre metódicas actividades físicas en la infancia y diversas capacidades intelectuales y parámetros de personalidad abren ancho campo a la pedagogía e incluso a la preocupación antropofilosófica.

A.lgunas formulaciones sencillas pueden ayudar a comprender esta nueva orientación que empieza a ser tenida en cuenta, aunque tímidamente, en ámbitos culturales e intelectuales:

El hombre es un ser corporal. Es cuerpo. Pero no es sólo cuerpo; porque tiene cuerpo. Hay en el hombre una conciencia del propio cuerpo. Es más que cuetpo. Pero no sólo su acción física es corporalizada, sino toda su acción en general. Su mismo ser y existir es un ser y existir corporal, corporalizado, corporeizado. El cuetpo del hombre es hombre mismo. La posesión, la tenencia que el hombre ha de su cuerpo no es como la de un objeto muy vinculado a él, pegado; ni incluso injertado, fusionado, asimilado. El hombre tiene cuerpo solamente porque es consciente de ello, no por distanciamiento sustancial ni accidental. El cuerpo no es un objeto-posesión del hombre, sino que es hombre mismo.

No hay hombre sin cuerpo; tampoco hay cuerpo humano sin hombre. El cuerpo del hombre muerto, el cuerpo humano sin vida, ya no es hombre; pero tampoco es un cuexpo animal, ni reliquia de un cuerpo puramente animal; es una reliquia humana (despojo de hombre) que existió sólo para ser hombre; no era organismo animal elevado a hombre, sino organismo humano, $\tan$ hombre como el resto de lo humano, aunque distinto de ello.

Estas balbuceantes formulaciones no son sino el intento de expresar la unidad en que consiste el ser humano. Pueden ser aceptadas por muy dis- 
pares concepciones filosóficas del hombre, desde un espiritualismo no angélico ni animista a un materialismo no maquinista. Parten de una conciencia fenomenológica experimentable a cualquier nivel de reflexión. Tienden a una superación del dualismo predominante durante siglos, no tanto en las puras formulaciones filosóficas cuanto en los convencionalismos sociocultu. rales, en las instituciones pedagógicas, en los reflejos morales, en la paremiología.

Los fenómenos más directamente relacionados con el cuerpo pueden encontrat ayuda en este entendimiento antropológico a la hora de buscar razones culturales. Tal sucede con esa singular conducta humana, voluminoso hecho social, que llamamos deporte.

\section{LA ANTIGUA INCOGNITA DEL DEPORTE}

El deporte es actividad del hombre total. Pero por ser actividad fúsica, es sensiblemente corporal.

La caza o el lanzamiento de jabalina hoy son conductas deportivas. Hubo un tiempo en que no eran deporte. Eran parte fundamental del repertorio de actos necesarios para vivir. Si no, el bomo de aquella época o el perteneciente a aquella tribu habrían sido devorados por las fieras o abatidos por las tribus enemigas. ¿Cuándo este esfuerzo predador se hizo venatorio? ¿Cuándo esta lucha guerrera se convirtió en agón del estadio? Si no sabemos fechas, al menos ¿cómo se produjo? He ahí un enigma gigantesco a cuyo esclarecimiento habrá que renunciar.

Hay un componente antropológico que podría set el mojón discrimina. torio de ambas conductas: la actitud lúdica. Esto puede orientarnos un poco pero no nos explica nada; porque el enigma del juego humano es aún mayor que el del deporte; precisamente por consistir en una más genérica conducta.

Los animales superiores juegan; es decir, producen conducta no directamente enderezada a la subsistencia. Una de las hermosuras de la naturaleza es el retozar de los cachorros mamíferos. Siguiendo la clásica intcrpretación de Groos, tal conducta lúdica se origina como garantía biológica en cuanto entrenamiento o adaptación a la vida. Pero el hombre, que desde su primerísima infancia se entrena para la vida en este juego biológico, lleva el juego mucho más allá. Invade con la marea lúdica todas sus capacidades culturales. El juego en el hombre liega desde la biología, pasando por la etología, a la cultura. La tesis huizingiana acerca del juego como 
origen de la cultura debe ser tetomada en una época en que se descubre la trascendencia humanística del ocio.

No se sabe aún cuándo empezó el hombre a realizar un juego cultural rebasando los exiguos repertorios del juego bioanimal. Las cavernas nos dan ya evidente prueba de un hombre culturalmente lúdico. Aun en la interpretación mágica - hoy mucho más discutida- de las pinturas rupestres, asoma una capacidad lúdica que origina arte. Fijar la imagen del bisonte en la roca para propiciar su abatimiento puede interpretarse como conducta utilitaria; pero aparece una exigencia de dibujo, una perfección, una morosidad y complacencia que nos hablan ya de verdadero deleite artístico, de lujo gratuito que rebasa ampliamente la toera utilidad de abatir la pieza. El cavernícola es ya un artista, un bomo ludens. Quizá la hostilidad del clima gélido y las largas jornadas de encierro aceleraron en rápidos milenios un proceso de interiorización y de enriquecimiento cerebral. Acaso el cavernícola fuera el primer hombre que realizó fecundas meditaciones y retiros.

El hacer del hombre, desde que éste alcanza lo que podríamos llamar una madurez filogenética, se derrama en dos grandes vertientes: la acción necesaria para vivir por un lado (caza, guerra, trabajo), y la acción superflua, deleitosa, gratificante, no directamente buscada ni realizada para la subsistencia. Esta segunda posee carácter lúdico. Cuando esta acción encauzada en la vertiente lúdica se concreta en esfuerzos o prestaciones físicas aparece el deporte.

Aquí se apunta solamente la raíz antropológica de este hecho tan com* plejo que hoy pasa de simple conducta humana a costumbres, instituciones, estructuras, sistemas sociales, con toda la complicación cultural que ello conlleva. Pero ahí está el origen de este hecho: actividad. física con talante gratuito; esfuerzo corporal nacido como juego.

En épocas antiguas con notable esplendor deportivo es difícil separar el contenido o sustancia estrictamente deportivo de otras connotaciones o vivencias, tales como lo religioso, lo guerrero, lo trágico. En grabados o inscripciones hoy catalogados como deportivos, tales como los nadadores y corredores de la tumba de Beni Hassan del antiguo Egipto (hacia el 3.000 a. de C.) o los luchadores y lanzadores sumerios (hacia el 2.900 a. de C.) no se puede hablar de costumbre o institución específicamente deportiva al modo socialmente parcelado como se entiende hoy esta institución. Se trata indudablemente de juegos de destreza o esfuerzo físico, bien calificados como auténticamente deportivos, pero enmarcados en vivencias y valoraciones bastante distintas de las que conocemos hoy día.

Organizaciones competitivas tan institucionalizadas y perfeccionadas como los Juegos de la Grecia prearcaica tenían una razón fúnebre. Aquiles organiza los más extraordinarios juegos para hontar a su difunto amigo $\mathrm{Pa}$. 
troclo. «Tú te hallaste en las exequias de muchos héroes cuando con motivo de la muerte de algún rey se ciñen los jóvenes y se aprestan para los juegos fúnebres», canta también Homero en la rapsodia 24 de la Odisea. Los mismos Juegos Olimpicos, cuya institucionalización definitiva se sitúa a comienzos del s. virı a. de $\mathrm{C}$. (unos dos sigios después de los cantos homéri$\cos$ ), nacen como solemnidades religioso-fúnebres. Más aún lo eran los Juegos Píticos, en Delfos. Vinculación a los «agones» trágicos tuvieron los Juegos fstmicos de Corinto.

Tampoco pueden separarse radicalmente las prácticas deportivas florecientes en pueblos de connotaciones institucionales guetreras. Muchos ejercicios deportivos son imitaciones de acciones guerreras. Aquí se plantea Ia incógnita de que las actividades deportivas hayan podido, en parte, nacer como un necesario adiestramiento para la guerra. Esta tesis podría estar avalada por el esencial talante agonístico del deporte. El programa más clásico de los Juegos de Olimpia (hubo a lo largo de los siglos diversas modificaciones y ampliaciones, que llegaron a sumar hasta 23 agones diferentes) ${ }^{2}$ consistía en carreras a pie (estadio, $192 \mathrm{~m}$., diaulo, ida y vueita, dólido, veinte largos), lucha, pugilato y pancracio, más el pentathlon, a su vez compuesto por catrera, salto, disco, jabalina y lucha. ${ }^{3}$ Todas eran actividades útiles para la guerra.

Quizá las primicias deportivas menos «beligerantes» sean las primitivas disputas de una bola (el «polo» mesopotámico, los juegos de pelota mesoamericanos, Ios ejercicios acuáticos de las familias faraónicas o los juegos de arte y destreza con el toro en Creta y posteriormente en las culturas ibéricas, aun cuando estas últimas tuviesen mucho que ver con el atte de esquivar a tan poderosa fera).

En los orígenes antropológicos de la conducta deportiva aparece cada vez más neta la raíz agonística. Pero la incógnita se ensancha: ejuega el hombre a competir para adiestrarse mejor con miras a la competencia a vida o muerte -es decir, se entrena - o somplemente repite a la hora del deporte en forma lúdica, recreativa, lo que en otros momentos necesita ejecutar para subsistir? Es, en el fondo, parte de la incógnita del juego humano: ¿entrenamiento biológico o remedo cultural $\longrightarrow$ creativo, inteligente- de acciones obligadas para subsistir? La respuesta a estas dudas constituiría una gran ayuda a la hora de valorar estas conductas humanas y de programarlas de cara a una sociedad determinada. Si el juego competitivo

2. C. Durantez, Olimpia y los Juegos Olimpicos antiguos, Ed. Comité Olímpico Español, Madrid, 1975, p. 165.

3. U. Popplow, Las épocas del deporte griego, en "Citius, Altius, Fortius», I, 1959 , p. 419. 
fuese un remedo o risa inteligente de la lucha guerrera, la tesis del deporte cono catarsis, como liberación o sublimación de la guerra lo convertiría en una costumbre altamente educativa y humanitaria. Siendo el hombre más deportivo se haría menos belicista. Es la teoría catártica de la agresión deportiva. Pero si fuese cierta la tesis contraria, el deporte competitivo sería peligroso porque alentaría en el hombre sus instintos guerreros.

No está, ní mucho menos, desvelado este enigma, ni por los estudios antropoculturales ni por las investigaciones de la moderna psicología sobre la conducta competitivo-deportiva. ${ }^{4}$ Parece que hubo un tiempo en que el hombre empezó a divertirse compitiendo. Las sociedades institucionalizaron estos juegos. Nacía eso que hoy llamamos deporte. Es ya un importante hecho cultural. Las raíces o razones antropológicas se pierden en la niebla de los siglos.

\section{III}

Este deporte, de tan incierta matriz antropológica, es uno de los grandes . protagonista de la sociedad del siglo $\mathrm{xx}$.

Muchas razones se han dado a esta explosión deportiva. Han predominado, debido principalmente a que el desbordamiento se produce en pleno siglo $\mathrm{xx}$, las explicaciones de moda en tal siglo, las sociológicas. Éstas, váIidas en general para múltiples esclarecimientos, no llegan a razones originales. El precedente apunte acerca de las perplejidades radicales del deporte tiene por objeto, simplemente, reforzar la conciencia de inseguridad, conveniente para no dogmatizar, y también para no descansar. Ahí quedan sin haber sido resueltas las más graves aporías. Y sirva también de tonalidad dominante o de leitmotiv que nos siga resonando en cualquier otra aventura explicativa. Los porqués de trasfondo filosófico no fueron invención pasada de moda. Si el hallazgo de respuestas técnicamente más vistosas, más gratificantes por su mejor accesibilidad, ha provocado cierta pérdida de sensibilidad indagatoria en los modos culturales vigentes, al menos quede la conciencia de que aquellos grandes porqués subsisten ahí, aparcados y aplazados, pero no desaparecidos.

Está más o menos admitido que la avasalladora colonización por patte del deporte a nuestra sociedad contemporánea obedece, en gran parte, a un cambio de sensibilidad con respecto al cuerpo. Se asiste a una mutación en la consideración personal del cuerpo y, a la vez - consecuentemente o concomitantemente-- en la protagonización social del cuerpo.

4. J. M. Cagigal, Deporte y agresión, Ed. Planeta, Barceiona, 1976. 
Frente a la consideración del cuerpó como soporte del espíritu -instrumento, base, condicionamiento material...-y, en una más radical interpretación, como enemigo del alma - cautiverio, destierro, cárcel...- hoy predominan las desinhibiciones. Se conjugan o se alternan diversos modelos existenciales: el cuerpo-placer; el cuerpo-comercio; el cuerpo-cosa; el cuerpoexhibición: el cuerpo-esplendor biológico; el cuerpo-naturaleza...

No se trata de formas rigutosamente nuevas de tratar el cuerpo. Hay antecedentes para todos los gustos en numerosas culturas. Lo que sí resulta nuevo es que en la civilización dominante (la que todavía, aunque forzadamente, puede denominarse civilización occidental, hoy más bien civilización del desartollo o del consumismo) ${ }^{\text {s }}$ se asiste a un desmelenamiento general del cuerpo; ha pasado en pocas décadas del banquillo de los acusados al pedestal de los dioses adorados.

La prodigiosa invasión del deporte obedece, en gran patte, a esta eclosión del cuerpo; mágico strip-tease cultural.

Es también el grito de alarma, de carácter socio-biológico, de una humanidad que protesta por la restricción de movimiento a que le ha sometido el tecnicismo.

Este segundo es un movimiento de carácter humanísticò -en la más pura acepción semántica. El otro puede ser el resultado de múltiples decepciones, dé un resquebrajamiento de valores, una éspecie de salida de prísión axiológica; es un complejo viraje moral, resultado de crisis destructiva o: de crisis regenerativa.

El gigante-deporte de nuestros días es traído y llevado por exhibicionismos políticos, por implacables poderes económicos de multinacionales, de supercomités. De esta situación ferial sacan provecho multitud de arribistas, pseudodirigentes, psèudotécnicos. Es uri gigantesco fanal donde se pringan golosos de toda calar̃a. Negociantes, vanidosos, inadaptados hallan en el multifacetismo del deporte remedio a mucho fracaso, impotencia', re. sentimiento o vacío. El deporte de nuestro tiempo es comó una sociedad paralela a la otra-sociedad organizada. Que "en muchos aspectos funciona mejor ${ }^{\dagger}$ que ésta, debido a la credibilidad lúdica que ofrece; a la necesidad mágica del pueblo, pero que por otra parte sirve de tefugio y compenṡación a múltiples inadaptaciones.

Pero por debajo de estas realidades, que la sociología analítica describe

5. La Lamada civllización occidental, dominante en el'muindo durante casí dos milenios, ha derivado en una puta civilización del desarrollo la producción de bie. nes, el bienestar material, la posesión). Tanto que hoy se dividen los pueblos en «desarrollados» y uen vías de desarrolio». La aparición del concepto y conciencia del «tercer mundo» puede signiffar una síntesis dialéctica superadora de esta dicotomía. Surgiría más bien como conciencia de un «nuevo mundo». 
magistralmente, existen metores más profundos, realidades antropológicas que las sustentan y dan vertebración: la necesidad de actividad corporal de un hombre cuya vocación de movimiento había sido frustrada por el relevo de su hija, luego aliada, luego usurpadora: la máquina. Y, en otro orden de razones, el cambio de significación moral y social del cuerpo. Una causa bioantropológica, y otra axiológica o antroposemiológica. Ambas cosas superpuestas, entrevaradas, coactuantes, existencialmente coetáneas.

En los movimientos pedagógicos que se inician en el siglo XvI (da Fel. tre, Mercurial, Vives...) y que alcanzan su cumbre con Rousseau y ia implantación inmediata, a finales del xvın, de las grandes escuelas gimnásticas europeas, ya se apuntaba esta valoración antropológica de lo corporal, pero concentrado en intuiciones educativas y reflexiones pedagógicas. La mundialización del deporte británico desde comienzos del $\mathrm{xx}$ supone, aunque por vía cultural distinta, nueva potenciación de la actividad corporal. Ambas corrientes (educativa y sociocultural) se encuentran en pleno siglo $\mathrm{xx}$, se refuerzan -no sin incidentes y mutuas incomprensiones- $y$ 'dan ocasión para que ciertas fuerzas dominantes se encarguen de vestir, adornar, maquillar a la rozagante criatura. Ésta -el deporte- se convierte en cierto modo en un objeto mimado de la sociedad del siglo xx.

Se pueden aplicar dos planes de observación a este llamativo hecho cultural:

El primero, más profundo, es la valoración antropológica del cuerpo; su redescubrimiento como potencial humano. Todo acto humano es corporeizado, sujeto a cuerpo; éste, el cuerpo, no es todo el hombre. Peto como hombre que es, ha de ser objeto de la máxima dignificación. A esta reconsideración antropológica del cuerpo hay que añadix la significación psicológica y cultural del juego, que precisamente la actual sociedad valora crecientemente reconociendo al fin las intuiciones educativas de los grandes pedagogos. Cuando este juego es físicamente activo, corporal, surge la actitud agonal, confrontativa, auto y hetero-experimentadora, auto y hetero-superadora: es el deporte. Por medio de esta actividad y de la resonancia social que desencadena, el hombre puede hallar cumplimiento a diversos imperatavos, como la descarga agresiva (Lorenz, Vinnai), la simbolización de conflictos (Beisser), la expresión ética (Plessner), el cumplimiento hedonístico (Bouet), la protección tribal (Morris), etc. La sociedad del siglo xx se ha topado con este hecho en desbordante desarrollo; es aquella joven criatura espléndidamente desarrollada. Nuevos impactos culturales y sociopolíticos van a acabar de transformarla y venderia.

El análisis de estos influjos constituye el segundo plano de observación, más superficial. Las características dominantes en una sociẻad determinada inciden en cualquier hecho significativo y dejan en él sus huellas. El consu- 
mismo, el imperialismo comercial, la especialización laboral con la consecuente mutilación personal, la hipervaloración de la cantidad y de la posesión sobre la calidad y la entidad y otras ebulliciones protagonistas de la macrosociedad del siglo $\mathrm{xx}$ han irrumpido en el deporte y lo han convertido, antes de que la criatura hubiese accedido a la plena aduitez, en objeto de comercio, poder, exhibicionismo, con todas las prostituciones que de ello hayan podido derivarse.

Sólo el recuerdo de algunas cifras descubre hasta qué punto el depotte actual es uno de los indicios de la desmesura de los poderes, económicos o políticos. Maradona ha costado al F. C. Barcelona cerca de los $1.000 \mathrm{mi}$ llones de pesetas. Hay jugadores de tenis, como Borg y McEnroe, que han ganado en un año, contando ingresos por publicidad cometcial, por encima de esa cifra. El montante económico alrededor del Mundial-82 de España (gastos, inversiones, comercialización) supera los 50.000 millones de pesetas. Unos mil quinientos millones de espectadores presenciaron por televisión las jornadas de inauguración y clausura.

Esta alborotada configuración del deporte de nuestro tiempo es la que atrae preferentemente la atención y, consecuentemente, reclama y obtiene razones. Éstas monopolizan las explicaciones del deporte contemporáneo. Son no sólo útiles, sino necesarias. Pero sin el recurso al otro plano de consideración difícilmente se obtienen esclatecimientos serios acerca de la fundamental dinámica que empuja el fenómeno deporte.

En los últimos veinte años proliferan interpretaciones dialéctico-sociales, tales como el deporte en cuanto alienación, en cuanto nuevo sector de la racionalización del trabajo (Habermas), en cuanto copia del mundo industrial (Plessner), en cuanto conformismo fagocitario, o, por el contrario,. como superación de la herencia alienante que el ciudadano arrastra (Oeschlägel), como tecurso reequilibrador a un subsistema social sui generis (Lüschen).

La consideración exigente de cada una de estas funciones conduciría a extensos y apasionantes estudios que rebasarían con mucho el propósito de esta escueta reflexión. Por el momento, valga como aportación la constatación de esta heterogeneidad de fuezzas antropológicas, culturales, sociales, que inciden en nuestro hecho, y, consecuentemente, la insuficiencia de cualquier interpretación simple. Ni la reflexión filosófica o antropológica son suficientes para explicar tantos y tan pintorescos productos como proliferan en el hodierno deporte; ni las mensuraciones y análisis sociológicos explican las raíces ni la vieja savia nutridora de tales sucesos; ni los estudios de la actual psicología son suficientes para aclarar esta singular conducta humana. Todos son rigurosamente necesarios para la comprensión del fenómeno. 
Volviendo al cuerpo, que es el origen de la presente reflexión, dos últi. mas consideraciones. La primera, que en el origen y en todo desarrollo del deporte, la filosofía del cuerpo está presente, como inhibidora o como propulsora.

La segunda, que el enorme desartollo y valoración del deporte deja, hoy por hoy, sólo patcialmente tocado el asunto del cuerpo. Ni en el deporte, ni en la escuela se ha aprendido - porque no ha sido enseñado- a asumir el cuerpo en su totalidad existencial, tal cual es dado, con sus limitaciones y carencias (alto, bajo, feo, bello, grueso, flaco, deforme, apolíneo, sano, enfermo...) sino a cultivar un cuerpo lo más joven posible, lo más bello posible. Ello es lícito, pero antropológicamente limitativo, parcial. El lema citius, altius, fortius tiene ambición y supone un estímulo de supera. ción; psicológicamente es estimulante; corporalmente es elitista, clasista, discriminatorio. Esta afirmación se hace a tenor de los resultados: el deporte, de hecho, entroniza en nuestra sociedad la marca, la performance, el campeonismo. Es una suerte de racismo. No casualmente el propio Coubertin, teólogo y pontífice a la vez del deporte del siglo xx formulaba específicamente la "selección tacial» como uno de los grandes objetivos del moderno olimpismo. Él se refería al mejoramiento por el deporte de la raza humana en general, de todos los hombres; pero el citius canoniza solamente -volyamos a los resultados- a los vencedores, detentadores mayoritariamente de espléndidos cuerpos.

Existen movimientos que intentan descubrit el más ancho cometido del deporte, tales como el «deporte para todos», el «segundo camino del deporte», la "gimnasia de mantenimiento», etc., con una concepción más humanitaria. Pero son todavía marginales ante la gran ola del deporte competitivo. Dan pie, al menos, a una esperanza no de que el deporte competitivo sea erradicado, cosa en cierta manera contradictoria, dada la esencia agonal del propio deporte, sino de que el competitivismo, es decir, la competición en sí como objetivo máxino, no sea excluyente de otras formas de vivir el deporte.

Con todo, mediante el deporte no se ha apuntado todavía a una pedagogía más profunda, ni siquiera mediante los citađos movimientos populares, la cual debería llevar a la aceptación plenamente asumida del propio cuetpo, tal cual éste sea. Quizás el deporte, pese a su radicación corporal, no sea el llamado a cumplir tal misión, más propia de la filosofía o de las religiones. La asunción plena y serena del cuerpo enfermo constituiría un aprendizaje a vivir verdaderamente mejor por la aceptación de los más difíciles momentos de vivir corporalmente, por los que todos, más o menos, hemos de pasar. La asunción del cuerpo viejo supone aún una más generali- 
«Rapers»: Revista de Sociologia

zada pedagogía, puesto que todo el que no muere prematuramente ha de pasar por tal experiencia existencial.

En la manera de entender y vivir la conducta deportiva, que es una de las formas de vivir más intensamente la propia corporalidad, quedan aún por diseñar notables riquezas personales.

No obstante, el deporte es el fenómeno mundial que pone de manifiesto el catacterístico entendimiento del cuerpo que asume el hombre de hoy. Para entenderlo, no se puede pasar por alto el estudio cultural del cuerpo, la significación que éste, como primordialidad antropológica, adquiere en nuestro tiempo. E igualmente, para la comprensión actual del fenómeno cuerpo, el deporte en todas sus dimensiones ofrece un valioso e imprescin. dible material. 